\title{
Evaluation of Landscape Change Using Remote Sensing: A Case Study of Burdur Lake
} Basin

\author{
Assist. Prof. Dr. Ahmet Benliay \\ Akdeniz University, Faculty of Architecture, Department of Landscape Architecture, Turkey
}

Abstract

\begin{abstract}
Georeferenced satellite images can be used for acquisition of topographic information, navigation and visualisation for various environmental studies. The objectives of this study were to determine land use and land cover changes and describe local landscape characteristics in the Burdur Lake Basin. Analyses were carried out using remotely sensed data. The topography of the land has been determined using GlobalDEM data of ASTER satellite with a resolution of $15 \mathrm{~m}$. With this data, ArcMap 10.3 ArcHydro plugin was used to identify the basin of Burdur Lake and it was accepted as the boundary of the study. LT51790341987245 (02 August 1987) and LT51790342011254 (11 August 2011) coded Landsat TM satellite images have been used in the study. For the orthorectification, a digital elevation model (DEM) with an RMS accuracy of ca. $3.5 \mathrm{~m}$, and for classifications 100 selected ground control points (GCPs) measured with differential GPS were used. Land uses identified with classified satellite images are analyzed in a spatial and proportional manner in a total study area of $3.361,56$ $\mathrm{km} 2$. The changes in land cover are compared with each other and have been evaluated in terms of landscape change. Population growth, rising water consumption for agricultural and domestic purposes and building dams has led to water surfaces declining from $208,71 \mathrm{~km} 2$ to $155,42 \mathrm{~km} 2$. Also analyses show that the landscape had been dominated by a mixture of urban and cultivated land, and became more homogenous and aggregated in in 24 years.
\end{abstract}

Keywords: Information technologies, change detection, landscape change, remote sensing

\section{Introduction}

Natural, cultural and ethnographic values are of great importance for sustainable development. The best way to use resources for both protection and development policies depends on assessing their susceptibility to changes (Benliay, 2009). Landscape is a dynamic phenomenon that almost continuously changes (Antrop, 1998). Landscape changes are thought to be driven by the complex interactions of socioeconomic (anthropic) and environmental (physical) factors (Forman, 1995; Zonneveld, 1995; Acosta et. al, 2005). The changes in landscapes become extremely devastating and many heritage values and resources become irreversibly lost. The speed of the changes, their frequency and magnitude increased unprecedented in the second half of the 20th century (Antrop, 2000).

Describing proportional changes of different land cover types though time may be crucial, not only for preserving biological diversity, but also for developing general landscape models which are useful in ecosystem management and environmental policies (Franklin, 1993; Christensen et al., 1996; Blasi et al., 2003; Acosta et. al, 2005). Remote sensing and the use of satellite imagery offer interesting possibilities for monitoring changes in land cover in a synoptic view (Antrop, 2004). Georeferenced satellite images can be used for acquisition of topographic information, navigation and visualisation for various environmental studies (Vassilopoulou et. al., 2002). Remote sensing and Geographical Information Systems (GIS), when integrated with the tools of landscape ecology, can be used to investigate the changing spatial patterns of biodiversity (Innes and Koch, 1998; Roy and Tomar, 2000; Rocchini et al., 2006).

In this study, Burdur Lake Basin land cover area and volume changes were analyzed by using Landsat satellite images of year 1981 and 2011 and the reasons for these changes were investigated. 


\section{MATERIAL AND METHOD}

\subsection{Material}

The study area is located in the Burdur Basin, which is one of the 25 hydrological basins in Turkey. The Burdur basin consists of six separate covered basins, including Acıgöl, Salda Lake, Yarışlı Lake, Akgöl and Atabey Plain along with Lake Burdur, which is the third largest lake in the Göller region (Ataol, 2010).

Burdur Lake Basin is located in the Western Mediterranean Region and is located between $37^{\circ} 59^{\prime} 47^{\prime \prime}-37^{\circ} 08^{\prime} 35^{\prime \prime} \mathrm{N}$ and $29^{\circ} 40^{\prime} 40^{\prime \prime}-30^{\circ} 29^{\prime} 21^{\prime \prime}$ E according to the Geographic WGS 84 coordinate system (Figure 1).

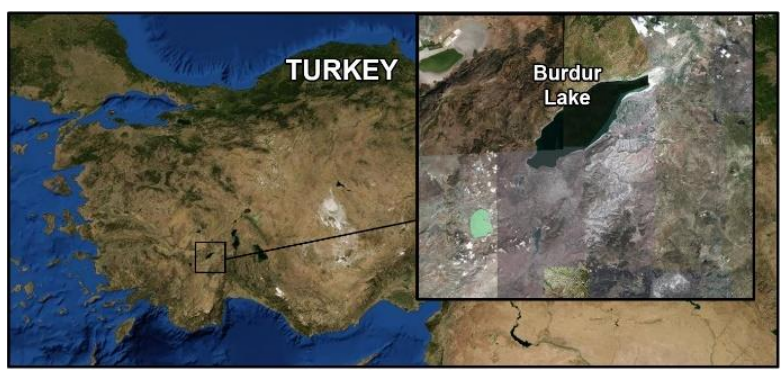

Figure 1. Burdur Lake Basin

GlobalDEM data of ASTER satellite with a resolution of $15 \mathrm{~m}$. has been used for creating topographic map of the study area. LT51790341987245 (August 2nd, 1987) and LT51790342011254 (August 11th, 2011) coded Landsat TM satellite images have been used for detecting the land cover of Burdur Lake Basin.

ArcMap 10.3 was used to create maps, orthorectification and classification of Landsat images. ArcMap 10.3 ArcHydro plugin was used to identify the basin of Burdur Lake.

\subsection{Method}

Development and conservation of water resources; it is a subject that needs to be considered in hydrological basin integrity and it is possible in the process of integrated watershed planning and management to be done on the axis of water production and consumption starting from production of quality water. The ArcHydro plugin of the ArcMap 10.3 software has detected a water basin along the water flow direction with a total of 3,361.56 km2 area.

In the study, land use exploitation was made from the earth's reflections. Seven of satellite images were combined into a single composite band. Satellite images were geographically corrected according to Arc MAP 10.3 software UTM (Universal Transverse Mercator) and North zone 35 system and nearest neighbor was taken as sampling method. This sampling method gives the most accurate result with minimum error in geo-rectification process.

In order to obtain land use by utilizing the satellite image, it is necessary to determine the actual landsape characteristics of the date on which the image was taken. This is a prerequisite for controlled classification. For the orthorectification, a digital elevation model (DEM) with an RMS accuracy of ca. $3.5 \mathrm{~m}$, and for classifications 100 selected ground control points (GCPs) which carried out between May 5th 2017 and April 8th 2017, measured with differential GPS were used.

The satellite images are defined by the "image classification" plug-in to the ArcMap software with coordinates of 100 points deducted for basin boundary and designated for controlled classification. The resulting images were visualized to confirm spatial data and additional points were added.

Land uses identified by classified satellite images are analyzed in a spatial and proportional manner, and the changes in land cover are compared with each other. These changes have been interpreted in terms of landscape change. 


\section{Results}

Five land cover categories were identified in the study area. These are forests, water surfaces, agricultural lands, settlements and finally dune areas. In addition forests were classified as Low, Middle and High for their vegetation values. Satellite images and maps showing their distribution in 1987 and 2011 are shown in Figure 2.

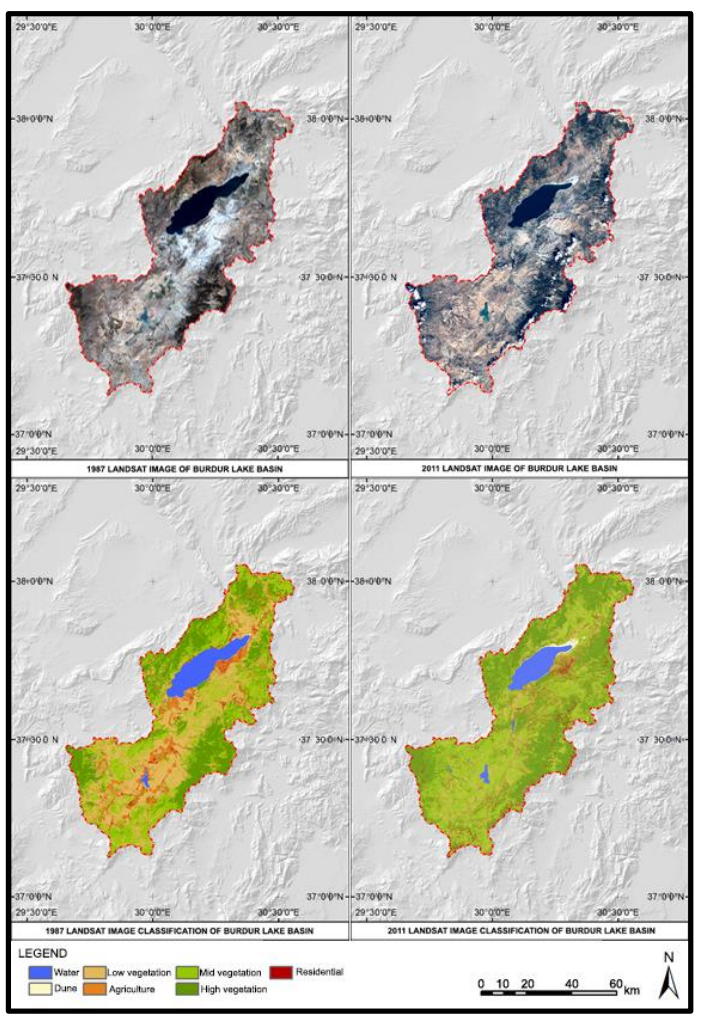

Figure 2. Landsat images and classifications of 1987 and 2011 in Burdur Lake Basin

According to the analysis, the land use which is the highest proportion in 1987 is the forests with low vegetation values with a ratio of $\% 32,42$. Other types of land use were determined as forests with medium vegetation values, high vegetation forests, water surfaces, agricultural land, settlements and finally dune fields, respectively. The pixel, areas and ratio values for 1987 Landsat Image Classification is given in the Table 1.

Table 1. Classification values for 1987 Landsat Image.

\begin{tabular}{|r|l|r|r|l|r|}
\hline \multicolumn{1}{|c|}{$\mathbf{9 8 7}$ Classification } & \multicolumn{1}{c|}{ PIXELS } & AREA $\left(\mathrm{km}^{2}\right)$ & \multicolumn{2}{c|}{ RATE (\%) } \\
\hline $\mathbf{1}$ & Water surface & 3.310 .431 & 208,71 & & $\mathbf{6} 21$ \\
\hline $\mathbf{2}$ & Dune & 92.992 & 5,86 & & 0,17 \\
\hline $\mathbf{3}$ & Low vegetation & 17.285 .496 & $1.089,78$ & & 32,42 \\
\hline $\mathbf{4}$ & Agriculture & 2.634 .288 & 166,08 & & $\mathbf{4}, 94$ \\
\hline $\mathbf{5}$ & Mid vegetation & 15.366 .242 & 968,78 & & 28,82 \\
\hline $\mathbf{6}$ & High vegetation & 13.070 .534 & 824,04 & & 24,51 \\
\hline $\mathbf{7}$ & Residential & 1.559 .241 & 98,30 & & 2,92 \\
\hline \multicolumn{2}{|c|}{ TOTAL } & $\mathbf{5 3 . 3 1 9 . 2 2 4}$ & $\mathbf{3 . 3 6 1 , 5 6}$ & & $\mathbf{1 0 0 , 0 0}$ \\
\hline
\end{tabular}

The land use which is the highest proportion in 2011 is the forests with mid vegetation values with a ratio of $\% 38,33$. Other types of land use were determined as forests with high vegetation values, low vegetation forests, water surfaces, agricultural 
land, settlements and finally dune fields, respectively. The pixel, areas and ratio values for 2011 Landsat Image Classification is given in the Table 2.

Table 2. Classification values for 2011 Landsat Image.

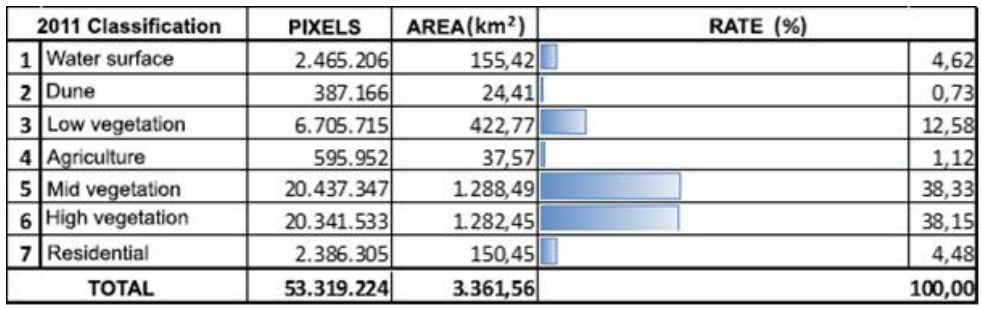

These values will not be sufficient to determine the landscape change in years. For example, same ratio and land area can change between agriculture to forest and forest to agriculture land use character in time for different locations in the basin. But this can not be considered as a no change situation. Not only the amount of land use changes but also spatial changes should be examined at the same time. For this, image difference analysis performed for the classified images. The image difference map for the classified images of 1987 and 2011 is given in Figure 3.

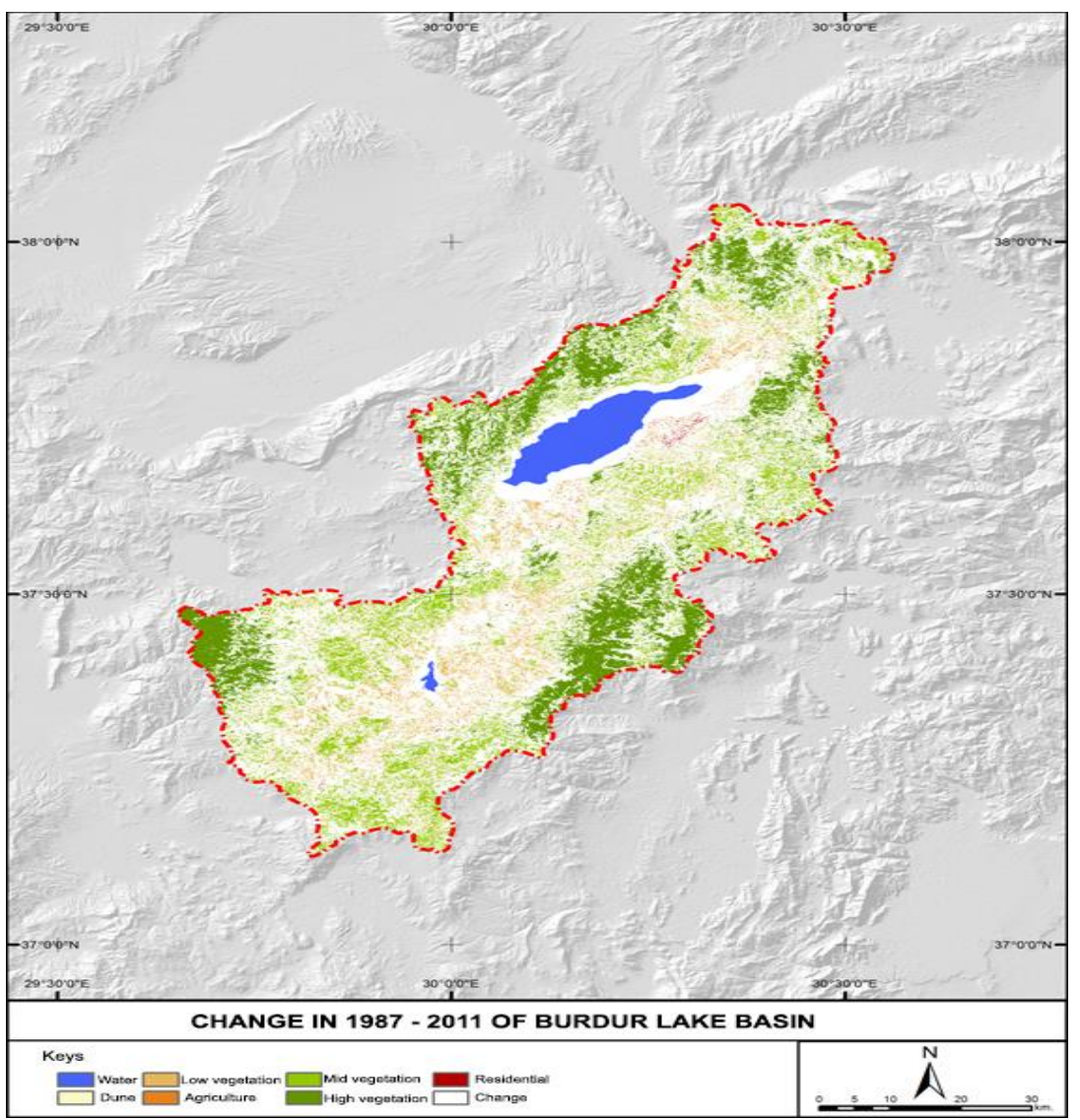

Figure 3. Land cover change in years 1987 ad 2011 in Burdur Lake Basin 
Table 3. Difference analysis for 1987 - 2011classifications.

\begin{tabular}{|c|c|c|c|c|c|}
\hline & & Change Situation & PIXELS & AREA $(\mathrm{km} 2)$ & RATE (\%) \\
\hline \multirow{7}{*}{ 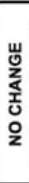 } & 1 & Water surface & 2.001 .603 & 126,19 & 3,75 \\
\hline & 2 & Dune & 4.159 & 0,26 & 0,01 \\
\hline & 3 & Low vegetation & 2.943 .622 & 185,58 & 5,52 \\
\hline & 4 & Agriculture & 81.785 & 5,16 & 0,15 \\
\hline & 5 & Mid vegetation & 6.693 .194 & 421,98 & 12,55 \\
\hline & 6 & High vegetation & 8.564 .933 & 539,98 & 16,06 \\
\hline & 7 & Residential & 101.257 & 6,38 & 0,19 \\
\hline \multirow{8}{*}{ 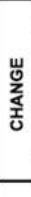 } & 1 & Water surface & 1.308 .828 & 82,52 & 2,45 \\
\hline & 2 & Dune & 88.833 & 5,60 & 0,17 \\
\hline & 3 & Low vegetaton & 14.336 .924 & 903,88 & 26,89 \\
\hline & 4 & Agriculture & 2.551 .958 & 160,89 & 4,79 \\
\hline & 5 & Mid vegetation & 8.687 .149 & 547,69 & 16,29 \\
\hline & 6 & High vegetation & 4.497 .339 & 283,54 & 8,43 \\
\hline & 7 & Residential & 1.457 .640 & 91,90 & 2,73 \\
\hline & & TOTAL & 53.319 .224 & $3.361,56$ & 100,00 \\
\hline
\end{tabular}

When the image difference analysis for the classified images of 1987 and 2011 examined, It has been seen that there is a significant change in the areas of the forest with low vegetation land covers. The rate of change is \% 26.89 and it is determined as $903.88 \mathrm{~km} 2$ area. Analysis shows that biggest type of change for these land use is for forest with medium vegetation with \% 15.89 and it is calculated as $534.03 \mathrm{~km} 2$ area and forest with high vegetation with \% 8.62 and it is calculated as $289.82 \mathrm{~km} 2$ area.

Forest with medium vegetation land cover has a variation of \%16.29 and the area is $547.69 \mathrm{~km} 2$. Biggest type of change for these land use is for forest with high vegetation with a ratio of \% 10.67 and it is calculated as $358.71 \mathrm{~km} 2$ area and forest with low vegetation with a ratio of $\% 3.60$ and it is calculated as $121.01 \mathrm{~km} 2$ area.

The forest with high vegetation have $283,54 \mathrm{~km} 2$ of area and has a ratio of change of $\% 8,43$. Biggest type of change for these land use is for forest with medium vegetation with a ratio of \% 5.69 and it is calculated as $191.35 \mathrm{~km} 2$ area and forest with low vegetation with a ratio of $\% 1.54$ and it is calculated as $51.62 \mathrm{~km} 2$ area.

The change in agriculture landscape is observed in a total area of $160.89 \mathrm{~km} 2$ and showing a change of $\% 4.79$. Biggest type of change for these land use is for forest with medium vegetation with a ratio of $\% 2.09$ and it is calculated as 70.21 $\mathrm{km} 2$ area and forest with high vegetation with a ratio of $\% 1.42$ and it is calculated as $47.70 \mathrm{~km} 2$ area.

The residential areas have been changed by $\% 2.73$ and as for the area, $91.90 \mathrm{~km} 2$ was found. Biggest type of change for these land use is for agriculture with a ratio of \% 1.27 and it is calculated as $42.59 \mathrm{~km} 2$ area.

Water surfaces show a change of $\% 2.45$. and determined as $82,52 \mathrm{~km} 2$ of landscape change. It has been seen that there is a notable change for dunes in water surfaces with a ratio of $\% 0,32$ and $10.62 \mathrm{~km} 2$ area and residental areas with a ratio of $\% 0,14$ and $4.62 \mathrm{~km} 2$ area.The dune landscapes shows the least changes by $\% 0.17$ and shows a change in the area of $5.6 \mathrm{~km} 2$.

In addition, when the areas where there is no change between the years 1987-2011 are examined; the one with the largest area is forest areas with high vegetation. It is observed that there is no change in these area of $539,98 \mathrm{~km} 2$ with a rate of $\% 16.06$. The forest with medium vegetation has a rate of $\% 12,55$ and no change in the area of $421,98 \mathrm{~km} 2$. The forest with low vegetation with a rate of $\% 5.52$ and no change in the area of $185,58 \mathrm{~km} 2$. The water surface has a rate of $\% 3.75$, with $126,19 \mathrm{~km} 2$ of area no change. Residental areas have a rate of $\% 0.19$ and no change in the area of $6.38 \mathrm{~km} 2$. Agricultural lands have a rate of $\% 0.15$ and area of $5.16 \mathrm{~km} 2$. The unchanged areas of sand dunes have $\% 0,01$ rate and area of $0.26 \mathrm{~km} 2$.

\section{CONCLUSION}

Urbanization has become ecologically complicated but geometrically simpler whereas the rural landscape became less abundant and diverse. Population growth, rising water consumption for agricultural and domestic purposes and building dams has led to water surfaces declining from $208.71 \mathrm{~km} 2$ to $155.42 \mathrm{~km} 2$ in Burdur Lake Basin. Depending on these outcomes, from 1987 to 2011, the lake lost about \% 25.53 of its surface area, as compared to the surface area in 1987. Decrease in water volume is $53.29 \mathrm{~km} 2$ and detected water surface change is $82.52 \mathrm{~km} 2$ in total landscape area. This 
result shows that there is an additional water surface gain of $29.23 \mathrm{~km} 2$ which was not a water surface before. The change in water surfaces volumes may be due to climatic factors or a consequence of human activities.

The results showed that in only \% 61.74 of total landscape there is no change in land use character. Also analyses show that the landscape had been dominated by a mixture of urban and cultivated land, and became more homogenous and aggregated in in 24 years. But vegetaton values of forests has risen over time and only this can be regarded as a gain in landscape character.

Acknowledging that the sources of the Burdur Lake and surroundings landscape change situation is multilayered in nature, thus requiring a multilevel solution. An appreciation of the direction and proportions of landscape change could help managers make the best use of available resources. Information derived from this kind of study should be taken into account when developing management policies and particularly when considering the possible ecological implications for biological diversity.

This study used remote sensing satellite image interpretation and GIS to detect and analyze the spatial changes and quantify the landscape change of Burdur Lake Basin. Using satellite images to extract information is faster and more accurate than other observation methods, particularly in identifying changes between two or more different time intervals. Also for Burdur Lake Basin, additional work must be done. Calculating and analyzing landscape metrics can enhance the results and detect the ecological consequences of urbanization.

\section{REFERENCES}

[1] Acosta, A., Carranza, M. L. and Giancola, M., 2005. Landscape Change and Ecosystem Classification in a Municipal District of a Small City (Isernia, Central Italy). Environmental Monitoring and Assessment (2005) 108: 323-335.

[2] Antrop, M., 1998. Landscape change: Plan or chaos? Landscape and Urban Planning. Volume 41, Issues 3-4, 6 July 1998, Pages 155-161.

[3] Antrop, M., 2000. Background concepts for integrated landscape analysis. Agriculture, Ecosystems \& Environment, 77(1-2), 17-28.

[4] Antrop, M., 2004. Landscape change and the urbanization process in Europe. Landscape and Urban Planning 67 (2004) 926.

[5] Blasi, C., Smiraglia, D. and Carranza, M. L., 2003. 'Analisi multitemporale del paesaggio all'interno di un sistema di classificazione gerarchica del territorio. II caso dei Monti Lepini (Italia Centrale),' Informatore Botanico Italiano 35(1), 31-41.

[6] Christensen, N. L., Bartuska, A. M., Brown, J. H., Carpenter, S., D'Antonio, C., Francis, R., Franklin, J. F., Mac Mahon, J. A., Noss, R. F., Parsons, D. J., Peterson, C. H., Turner, M. G. and Woodmansee, R. G., 1996. 'The report of the Ecological Society of America committee on the scientific basis for ecosystem management,' Ecol. Appl. 6, 665-691.

[7] Franklin, J. F., 1993. 'Preserving biodiversity: Species, ecosystems or landscapes? Ecological Applications, 3, pp. 202-205.

[8] Forman, R. T. T., 1995. Land Mosaic, Cambridge University Press, Cambridge.

[9] Innes, J.L., Koch, B., 1998. Forest Biodiversity and its Assessment by Remote Sensing. Global Ecol. Biogeogr. Lett. 7, 397419.

[10] Rocchini D, Perry G. L.W., Salerno M., Maccherini S., Chiarucci A., 2006. Landscape change and the dynamics of open formations in a natural reserve. Landscape and Urban Planning 77 (2006) 167-177.

[11] Roy, P.S., Tomar, S., 2000. Biodiversity Characterization at Landscape Level Using Geospatial Modelling Technique. Biol. Conserv. 95, 95-109.

[12] Vassilopoulou, S., Hurni, L., Dietrich V., Baltsavias, E., Pateraki, M., Lagios, E., Parcharidis, I., 2002. Orthophoto Generation Using IKONOS Imagery and High-Resolution DEM: A Case Study on Volcanic Hazard Monitoring of Nisyros Island (Greece). ISPRS Journal of Photogrammetry and Remote Sensing. Volume 57, Issues 1-2, November 2002, Pages 24-38.

[13] Zonneveld, I. S.. 1995. Land Ecology: An Introduction to Landscape Ecology as a Base for Land Evaluation, Land Management and Conservation, SPB Academic Publishing, Amsterdam. 